\title{
Rituals in Service: A Literature Review
}

\author{
Qian Liu, Haiying Wei \\ School of Management, Jinan University, Guangzhou, China \\ Email: LQ792579679@163.com
}

How to cite this paper: Liu, Q. and Wei, H.Y. (2020) Rituals in Service: A Literature Review. Journal of Service Science and Management, 13, 178-187.

https://doi.org/10.4236/jssm.2020.131012

Received: January 3, 2020

Accepted: February 24, 2020

Published: February 27, 2020

Copyright $\odot 2020$ by author(s) and Scientific Research Publishing Inc. This work is licensed under the Creative Commons Attribution International License (CC BY 4.0).

http://creativecommons.org/licenses/by/4.0/

\begin{abstract}
Although service rituals are widely used in service practice, theory researches on them have not received enough attention. Service rituals are a series of process-based, repeatable, symbolic actions that occur during the service contact process and are usually provided by enterprises or service personnel. By sorting out relevant literature, this article defines the concept and classification of service rituals. Service rituals can enhance consumer experience, enhance customer-enterprise relationship and promote brand value, and the cultural background of consumers will affect their service ritual experience. At the end of this paper, the future research directions of service rituals are proposed. The future researches should aim to deepen qualitative research, increase empirical research, and explore influencing factors.
\end{abstract}

\section{Keywords}

Service Rituals, Concept, Effect

\section{Introduction}

The service profit chain states that customer satisfaction and loyalty are the basis for service companies to gain profits [1]. Given the important role that customers play in the profitability of enterprises, how to achieve customer satisfaction and gain loyal customers become the focus of the academic and the industry. Among them, the improvement of service design and customer experience are classic topics in this field, therefore, some service management tools have become necessary for enterprise service practice, such as designing service blueprints to standardize service processes, applying service quality model to find the gap between customer expectation and service quality [2] [3]. However, with the improvement of the basic service level in service industry, services of businesses seem to similartaxis, and these tools seem to be gradually unable to meet higher requirements of consumers. What they need now are more personalized and 
memorable services. Based on this, many scholars have proposed to confer services meanings, one of which is the application of rituals [4].

Ritual refers to a series of symbolistic activities that occur in a fixed sequence and can be repeated [5]. In fact, the service ritual phenomenons have sprung up. For example, Japanese shopping malls have opening ritual, the ultimate etiquette is admirable. In China, before the consumer tastes the "beggars chicken", he knocks it three times with a mallet, which means good luck. These unique service forms all belong to service rituals. Previous studies have shown that customers can obtain the dual value of basic products and joyful emotions in this process. However, observing online comments, we find that not all service rituals cause positive effects, inappropriate rituals may compromise the quality of service. Meanwhile, compared with practice, the theoretical researches of service rituals seem a little lagged behind. With the prevailing service dominant logic, service companies need to continuously innovate service forms, and create differentiated services in order to meet the increasing expectations of customers. Thus, exploration on service rituals will play an important role in improving customer experience and business performance.

In sum, service ritual is a brand new concept, whose theoretical development is in its infancy. Exploration on service rituals, on the one hand, can not only enrich the theoretical research of ritual, but also provide new ideas for related researches on service design and service innovation. On the other hand, it can also help service companies to design effective service. Given the importance of service rituals, this article will detail its concept and current research status, propose future research directions, and strive to provide inspiration for theoretical development in this field.

\section{Concept and Classification of Service Rituals}

\subsection{Ritual}

The concept of service ritual, which is, by its nature, service provided by a service organization with ritual elements and ideas applied, originates from ritual. Therefore, a simple combing of ritual helps to deepen the understanding of the meaning of service rituals.

Ritual originated from anthropology, sociology, and later extended to the fields of psychology and management, showing an expanding trend from sacred to mundane. Sacred rituals are more narrowly defined, they often carry a certain mysterious color, and emphasize the special aspects of special groups or the role of supernatural forces, for example, the existence of gods is a prerequisite for human perceiving ritual to be effective [6] [7] [8]. The studies of secularized rituals are more generalized. In such papers, rituals are not the exclusive property of religion, they can be expressed in all areas of human life: tourism, which is considered to transform experience, is a kind of ritual; daily behaviors such as make-up, grooming, and greetings that are given meaning are rituals; collective carnivals at sports events and festivals are also a ritual; even retail and service 
experiences are conceptualized as mundane leisure consumption rituals [9] [10] [11] [12].

Previous researches have suggested that sequence of actions, repetitiveness, symbolic meaning, and non-functionality are important characteristics to define ritual [13] [14]. No matter simple or complex, the form of ritual should be a series of movements. By exploring Simpatias, a ritual of exorcising bad luck in Brazil, Legare \& Souza [8] found that repetitive behaviors and multiple steps are very important, they are the key precursors to promote the effectiveness of ritual. In addition, the ritual behavior is symbolic and usually has no direct relationship with the purpose of the ritual. Contrary to the ritual execution strictly according to the script, habits or routine behavior often change, there is no symbolic meaning in these functional behaviors [15]. For example, in daily life, the position and order of tableware are not important, but during the Jewish Passover feast, tableware must be carefully placed, even if it is not useful to make food more delicious [16].

\subsection{Concept of Service Rituals}

As early as the 1970s, scholars paid attention to ritualization in service field. Based on the characteristics of ritualized processes, Kottak [17] proposed that McDonald's standardization is a ritual experience. Siehl, Bowen and Pearson [18] introduced the concept of rituals into specific service contacts process, and proposed integration ritual, which is composed of language, emotion, ritualized behavior, physical environment and so on. Johns [19] believes that the interaction between frontline employees and customers has scripted characteristics, which can be regarded as rituals. On the basis of previous studies, Otnes, Ilhan and Kulkarni [20] proposed the rudiment of the concept of service ritual: "planned, symbolic, performative and often repeated activity that providers execute for and with customers, to enhance customer experiences and achieve marketing goals".

Although the existing literature has not uniformly defined service ritual, the three major characteristics of the service rituals can be identified through literature review [21]. Action serialization. Consistent with ritual, sequence is an important characteristic of service ritual, which is mainly reflected in the sequence and repetition of ritual actions. Symbolic. The symbolism of service ritual is mainly reflected in its cultural significance. The diction and behaviors in rituals can be regarded as symbols, implying various value information and cultural traditions. For example, "knock three times" before tasting beggars chicken means good luck. Performability. Service rituals have fixed scripts, actors and spectators. As service performers, the service personnel must perform the script and behavior according to the script settings.

Based on Rook's statement that ritual is composed of objects, scripts, performer and audience, four elements of serving ritual scene are as follows [5]. First, objects. They are consumed during service ritual, such as food, wine, diamond rings, candles, etc., and can convey symbolic information. Second, script. It plays 
a guiding role in service ritual, which specifies the way customers and employees interact, and clarifies which consumer products will be used, and the order in which behaviors occur. Third, performer's role. Service ritual scripts are performed by individuals who play various ritual roles. Frontline employees and customers participating in the ritual all play certain roles in the ritual process. For example, employees can be customers' enthusiastic "friends", or intimate “servants". Fourth, audience. Improving customers' consumption experience is an important mission of service ritual, so customers are often the target audience.

Now we further understand the concept of service ritual through the comparison of service ritual and consumption ritual. First of all, service rituals mainly take place in service scenes, while scenes of consumption rituals are more diversified, such as home, tourist destinations and various marketing sites [9] [22]. Second, interaction between customers and service personnel is one of the characteristics of service rituals, while consumption ritual focuses more on the interaction between consumers [23] [24]. Third, from the perspective of implementation intention, service rituals are designed by enterprises to serve the management of customer relationship, while consumption rituals generally emphasize the voluntary participation of consumers, and the purpose of participation is to benefit from the rituals, such as social benefits [25]

\subsection{Classification}

There are two Classification criteria when classifying service ritual types. One is the complexity of ritual actions, and the other is the content of ritual.

First, complexity of ritual actions. Rituals have the characteristics of action steps, and the number of steps represents the complexity of rituals. According to this, rituals can be divided into simple, moderate, and elaborate. Actions in simple ritual are easy and require less, while elaborate ritual should have more steps and stricter execution rules, moderate rituals are in between. The effects of ritual are different with different complexity [26]. Similarly, different service rituals have different degrees of complexity. It can be a simple greeting or a series of complex behaviors that instigate the emotions of customers. Low-ritualized-level service has a single ritual flow and a concise logic, the process of moderate level ritual is richer and the logic complexity is slightly enhanced, the process of high level ritual is redundant and the logic is more complicated [21]. This classification helps companies find the right service ritual. For example, when "quickness" is the goal of service, simple service rituals are often more customer-friendly. At this time, waiters only express task-related behaviors and languages, and in service scenarios that require customer participation, more in-depth communication with customers is essential [18]. Although service ritual can be divided according to the number of steps, so far, relevant researches have not defined the specific values of low, medium, and high ritualization. The three different degrees of comparison are only relative terms. 
Second, content attributes. In addition to the number of action steps, scholars also divided ritual from its script content. Otnes, Ilhan and Kulkarni [20] conducted a survey of rituals in service places. Business owners recalled some ritual-related behaviors provided by the service organization. Finally, six types of service ritual were summarized, namely commemoration, gift giving, greeting, incitement, farewell, and inspiration. 1) Commemoration. The commemorative type involves companies or employees participating in important moments of the customer's life, such as providing service support for customers' proposal ceremonies or giving customers birthday blessings. 2) Gift-giving. It includes providing customers with free or unexpected goods or services, such as giving desserts, small gifts. 3) Greeting. Employee should express gratitude to customers who entered the service place. 4) Incitement. In this type, collective excitement will be generated for the customers gathered by executing the established script. 5) Farewell, which mainly means thanking customers again when they leave. 6) Inspiring. This type of service ritual is designed to help customers build knowledge of a product and create sales opportunities. Although the scholar team has made a detailed division on the category dimension of service ritual, it seems that this classification method is difficult to fully cover all service rituals and needs to be further improved, considering the limited number of service organizations interviewed and the increasing application of rituals in company's practice in recent years.

\section{Effects of Service Ritual}

What are the positive effects of service ritual, and what are the negative effects if it is not implemented properly? The answer to this question is helpful to provide directions for enterprises and subsequent researches.

\subsection{Positive Effects}

The study process of service ritual is still in its infancy. Most studies use qualitative methods to explore the effects of service rituals, and focus more on positive effects.

Enhance consumer experience. Studies have shown that consumers are more inclined to remember special events that are not common in their lives [27]. Adding ritual elements to services will make consumers perceive the service as distinctive, so consumers will have a deeper memory of the service scene. As a special service designed by the company, service ritual is conducive to create an environment and become an important part of customer experience management. Underwood, Bond and Baer [28] pointed out that restaurants can use rituals to express theme and atmosphere. For example, the Lambert restaurant uses a roll-tossing ritual to shape an informal service atmosphere and enhance consumers' perception of pleasure. A survey of classical concert pointed that classical concert may be boring for common audiences, but as one of the service elements, using ritual can effectively reduce the distance between the listener and the environment and enhance their immersive experience, with the correct implemen- 
tation of the service staff at the concert [29]. Cervellon and Coudriet [30] found in interviews with consumers that luxury stores are similar to sacred churches, and service ritual is an effective measure to create a sense of respect. For example, the service personnel have an exclusive ritualized role-"ambassadors", they are the guardians of the customer's dream, they should be courteous and professional. Welcome and farewell are especially important on this occasion. In addition, various ritualized objects, such as white gloves, exquisite display stands, add a sense of treasure and sacredness to the product.

In the fierce market competition, customer relationship management is particularly important. Previous research has suggested that service ritual maybe a powerful weapon to enhance the relationship between consumers and the enterprise. Siehl, Bowen and Pearson [18] believe that in service contact, employees will follow the script of ritual to show the right mood, which helps to improve customer satisfaction. At the same time, language, postures, ritualized behavior can promote an appropriate intimacy between employees and customers, and enhance customers' willingness to participate in interactions. Otnes, Ilhan and Kulkarni [20] explored the role of language in service ritual, and drew the conclusion that by means of ritual language, companies can improve customer satisfaction and loyalty and establish friendship with customers. In particular, when customers think that the products and services provided by the company have high value, this friendship will be closer. For example, giving gifts to customers makes them feel special and trust more in company. In addition, empirical research shows that ritual helps the formation of group notion, and participants who participate in the same ritual will be more united, so in successful service rituals, consumers may generate a sense of trust to brand and view employees as members in the group, enhancing consumers' willingness to interact with the company [16] [31].

Consumers' positive awareness of service rituals can extend to brands. Sharma, Kumar and Borah [32] suggested that the ritual is a strategic tool for brand internationalization and can be more easily accepted by local consumers. Having collecting corporation data in the catering and retail industries, they finally found that the brands with implementation of service rituals had better performances in the market than brands without ritual. Meanwhile, some scholars proposed that service rituals could be used as a predictor of brand well-being [21].

To sum up, service rituals provide added value to customers. They can enhance the consumers' service experience and strengthen consumers' memory of service. Further, customers increase their satisfaction with the company, deepen their relationship with the enterprise, and establish a foundation for building a competitive brand.

\subsection{Negative Effects}

Although the original intention of the corporate designing service rituals is to win the favor of consumers, not all service rituals can bring positive emotions to customers. 
First of all, it is difficult to increase customer's immersion if service rituals could not be understood by them, and for worse, may even reduce their consumption pleasure, and produce negative effects [29]. As some empirical studies suggest, only when consumers understand the meaning of a series of actions can positive psychological aftereffects be generated [13] [33].

In addition, consumers do not accept everything, they will also refuse to participate in the service ritual, such as identity positioning resistance and identity protection resistance, consumers holding the former concept will consider whether the meaning of the ritual is consistent with the identity positioning they expect, while consumers who hold the second point of view mainly resist the negative feelings such as embarrassment and sadness experienced through the ritual [34]. Sometimes ritual will make noise, which can easily cause customers to feel a sense of privacy infringement and restraint, and lead to negative emotions such as embarrassment and resentment. Therefore, they hope to avoid service providers in the future [35]. In addition, service rituals will inevitably complicate the service process while fine-tuning the service. Some consumers mention that service ritual complicate eating process, and the ritual content does not match the theme, so the entire ritual process becomes embarrassing.

From what has been discussed above, we identify that service rituals can enhance the consumers' service experience, which benefit brand by deepening consumers' relationship with the enterprise. But inappropriate service ritual also may cause negative effects. Undesirable rituals may have the following characteristics: service ritual could not be understood by customers, the meaning of ritual is not consistent with the identity positioning which customers expect, ritual is noisy.

\section{Conclusion and Future Research Prospects}

\subsection{Conclusion}

Up to now, there are still few theoretical studies on service rituals, but relevant studies are of great significance to enterprise practice. Therefore, this paper comprehensively sorts out the literature of service ritual in order to provide a basis for future research. Through literature review, this paper firstly discusses the definition, elements and classification of service ritual on the basis of elaborating the concept of ritual, and then identifies the effects of service ritual, including positive effects and negative effects. On the one hand, service rituals can improve customer experience and enhance brand competitiveness of the service enterprise, which have enlightening effect on enterprise's service innovation. On the other hand, service rituals are not omnipotent, enterprises should avoid some unsatisfactory service rituals in the implementation process.

\subsection{Future Research Prospects}

Although service rituals exist widely in practice, researches on this topic in academic circle are still very limited, and there is still ample space for research in this field. 
First, although predecessors have conducted preliminary discussions on service rituals in qualitative studies, foreign research has not been thorough enough so far. The same is true in China. Although there are many ritual phenomena in service, related researches are limited to themed restaurants, and most contents are ritualization of service scenarios, while discussions of ritual behavior in service contact are rare. Therefore, in the future, we can continue to conduct interviews and follow-ups from the perspective of consumers, employees, and enterprises, and fully explore the phenomenon and nature of service rituals for the development of subsequent service ritual theories.

Second, design service ritual experiments and conduct empirical researches on the after-effects of service rituals. Empirical researches of service rituals are in the empty window period. If empirical researches are introduced, the first problem to be solved is how to scientifically design experiments of service ritual. Future service ritual experiments could be designed with reference to existing ritual experiments. After that, it is also necessary to discuss the effects of the service ritual. On the one hand, the positive impacts of service ritual need to be further explored, for example, it may enhance the perception of authenticity of established brands. On the other hand, future researches should also deepen the discussion of the negative impacts on service rituals. Legare and Souza [8] mentioned that the complexity of rituals affects the effectiveness of ritual perception. Therefore, different levels of service rituals may have different effects. Simple service rituals may be easily ignored by consumers, and too many steps in service ritual may bring consumers a sense of tediousness and curb consumer pleasure. In addition, in the author's interviews with consumers, some people said "the sudden gongs and drums sounds of the Northeast restaurant are very annoying" "Some ritualized language or actions make people feel friendly, while others make people feel hierarchy and uncomfortable". It can be seen that when service rituals make the environment noisy and bring hierarchy, they may present negative effects.

Third, since service ritual may have double-sided effects, how can we strengthen its positive effects and avoid negative aftereffects? Discussions on this issue helps companies to solve practical problems, thus future research can strengthen the discussion of factors affecting the success of service rituals.

\section{Conflicts of Interest}

The authors declare no conflicts of interest regarding the publication of this paper.

\section{References}

[1] Loveman, G.W. (1998) Employee Satisfaction, Customer Loyalty, and Financial Performance: An Empirical Examination of the Service Profit Chain in Retail Banking. Journal of Service Research, 1, 18-31. https://doi.org/10.1177/109467059800100103

[2] Shostack, G.L. (1993) How to Design a Service. European Journal of Marketing, 16, 49-63. https://doi.org/10.1108/EUM0000000004799

[3] Brogowicz, A.A., Delene, L.M. and Lyth, D.M. (1990) A Synthesised Service Quality 
Model with Managerial Implications. International Journal of Service Industry Management, 1, 27-45. https://doi.org/10.1108/09564239010001640

[4] Matthews, T. (2017) Sacred Service: The Use of "Sacred Theory" in Service Design. Journal of Design, Business \& Society, 3, 67-97. https://doi.org/10.1386/dbs.3.1.67_1

[5] Rook, D.W. (1985) The Ritual Dimension of Consumer Behavior. Journal of Consumer Research, 12, 251-264. https://doi.org/10.1086/208514

[6] Ahler, J.G. and Tamney, J.B. (1964) Some Functions of Religious Ritual in a Catastrophe. Sociological Analysis, 25, 212-230. https://doi.org/10.2307/3710553

[7] Barrett, J. and Lawson, E.T. (2001) Ritual Intuitions: Cognitive Contributions to Judgments of Ritual Efficacy. Journal of Cognition and Culture, 1, 183-201. https://doi.org/10.1163/156853701316931407

[8] Legare, C.H. and Souza, A.L. (2012) Evaluating Ritual Efficacy: Evidence from the Supernatural. Cognition, 124, 1-15. https://doi.org/10.1016/j.cognition.2012.03.004

[9] Gentina, E., Palan, K.M. and Fosse-Gomez, M.H. (2012) The Practice of Using Makeup: A Consumption Ritual of Adolescent Girls. Journal of Consumer Behaviour, 11, 115-123. https://doi.org/10.1002/cb.387

[10] Hummon, D.M. (1988) Tourist Worlds: Tourist Advertising, Ritual, and American Culture. The Sociological Quarterly, 29, 179-202. https://doi.org/10.1111/j.1533-8525.1988.tb01250.x

[11] Hartman, K.B., Meyer, T. and Scribner, L.L. (2009) Retail and Service Encounters: The Inter-Cultural Tourist Experience. Journal of Hospitality Marketing \& Management, 18, 197-215. https://doi.org/10.1080/19368620802591934

[12] Tsiotsou, R.H. (2016) A Service Ecosystem Experience-Based Framework for Sport Marketing. The Service Industries Journal, 36, 478-509. https://doi.org/10.1080/02642069.2016.1255731

[13] Brooks, A.W., Schroeder, J., Risen, J.L., Gino, F., Galinsky, A.D., Norton, M.I. and Schweitzer, M.E. (2016) Don't Stop Believing: Rituals Improve Performance by Decreasing Anxiety. Organizational Behavior and Human Decision Processes, 137, 71-85. https://doi.org/10.1016/j.obhdp.2016.07.004

[14] Vohs, K.D., Wang, Y., Gino, F. and Norton, M.I. (2013) Rituals Enhance Consumption. Psychological Science, 24, 1714-1721. https://doi.org/10.1177/0956797613478949

[15] Stambulova, N., Stambulov, A. and Johnson, U. (2012) "Believe in Yourself, Channel Energy, and Play Your Trumps": Olympic Preparation in Complex Coordination Sports. Psychology of Sport and Exercise, 13, 679-686. https://doi.org/10.1016/j.psychsport.2012.04.009

[16] Hobson, N.M., Schroeder, J., Risen, J.L., Xygalatas, D. and Inzlicht, M. (2018) The Psychology of Rituals: An Integrative Review and Process-Based Framework. Personality and Social Psychology Review, 22, 260-284. https://doi.org/10.1177/1088868317734944

[17] Kottak, C.P. (1978) Rituals at McDonald's. Journal of American Culture, 1, 370-376. https://doi.org/10.1111/j.1542-734X.1978.0102_370.x

[18] Siehl, C., Bowen, D.E. and Pearson, C.M. (1992) Service Encounters as Rites of Integration: An Information Processing Model. Organization Science, 3, 537-555. https://doi.org/10.1287/orsc.3.4.537

[19] Johns, N. (1999) What Is This Thing Called Service? European Journal of Marketing, 33, 958-974. https://doi.org/10.1108/03090569910285959

[20] Otnes, C.C., Ilhan, B.E. and Kulkarni, A. (2012) The Language of Marketplace Rituals: Implications for Customer Experience Management. Journal of Retailing, 88, 
367-383. https://doi.org/10.1016/j.jretai.2012.02.002

[21] Wei, H.Y., Wang, Y., Ran, Y.X., Zhang, Y.S. and Shu, L.F. (2018) Effects of Service Ritual on Brand Well-Being: Based on the Interaction Ritual Chain Theory. Advances in Psychological Science, 26, 1141-1151. (In Chinese)

https://doi.org/10.3724/SP.J.1042.2018.01141

[22] Rocha, A.R.C., da Rocha, A. and Rocha, E. (2017) Rituals of Cruise Consumption and the "New" Middle Class: Desiring and "Devouring" Maritime Cruises. Leisure Studies, 36, 468-480. https://doi.org/10.1080/02614367.2016.1182205

[23] Khan, A., Lindridge, A. and Pusaksrikit, T. (2018) Why Some South Asian Muslims Celebrate Christmas: Introducing "Acculturation Trade-Offs". Journal of Business Research, 82, 290-299. https://doi.org/10.1016/j.jbusres.2017.07.023

[24] Wallendorf, M. and Arnould, E.J. (1991) "We Gather Together": Consumption Rituals of Thanksgiving Day. Journal of Consumer Research, 18, 13-31. https://doi.org/10.1086/209237

[25] Gainer, B. (1995) Ritual and Relationships: Interpersonal Influences on Shared Consumption. Journal of Business Research, 32, 253-260. https://doi.org/10.1016/0148-2963(94)00050-O

[26] Hobson, N.M., Gino, F., Norton, M.I. and Inzlicht, M. (2017) When Novel Rituals Lead to Intergroup Bias: Evidence from Economic Games and Neurophysiology. Psychological Science, 28, 733-750. https://doi.org/10.1177/0956797617695099

[27] Herz, M. and Brunk, K.H. (2017) Conceptual Advances in Consumers' Semantic and Episodic Brand Memories: A Mixed Methods Exploration. Psychology \& Marketing, 34, 70-91. https://doi.org/10.1002/mar.20974

[28] Underwood, R., Bond, E. and Baer, R. (2001) Building Service Brands via Social Identity: Lessons from the Sports Marketplace. Journal of Marketing Theory and Practice, 9, 1-13. https://doi.org/10.1080/10696679.2001.11501881

[29] Carù, A. and Cova, B. (2006) How to Facilitate Immersion in a Consumption Experience: Appropriation Operations and Service Elements. Journal of Consumer Behaviour. An International Research Review, 5, 4-14. https://doi.org/10.1002/cb.30

[30] Cervellon, M.C. and Coudriet, R. (2013) Brand Social Power in Luxury Retail: Manifestations of Brand Dominance over Clients in the Store. International Journal of Retail \& Distribution Management, 41, 869-884. https://doi.org/10.1108/IJRDM-01-2013-0016

[31] Longstaff, E. (2017) Ritual in Online Communities: A Study of Post-Voting in MOOC Discussion Forums. International Journal of Human-Computer Interaction, 33, 655-663. https://doi.org/10.1080/10447318.2016.1277639

[32] Sharma, A., Kumar, V. and Borah, S.B. (2017) Ritualization: A Strategic Tool to Position Brands in International Markets. Journal of International Marketing, 25, 1-24. https://doi.org/10.1509/jim.16.0104

[33] Zhang, Y., Risen, J.L. and Hosey, C. (2014) Reversing One's Fortune by Pushing Away Bad Luck. Journal of Experimental Psychology: General, 143, 1171-1184. https://doi.org/10.1037/a0034023

[34] Tinson, J., Close, A., Tuncay Zayer, L. and Nuttall, P. (2013) Attitudinal and Behavioral Resistance: A Marketing Perspective. Journal of Consumer Behaviour, 12, 436-448. https://doi.org/10.1002/cb.1445

[35] Otnes, C., Crosby, E., Kwon, M. and Chinchanachokchai, S. (2011) The Impact of Aesthetics in Embedded Service Rituals. In: Bradshaw, A., Hackley, C. and Maclaran, P., Eds., European Advances in Consumer Research, Vol. 9, Association for Consumer Research, Duluth, MN, 23. 